Plant Tissue Cult. \& Biotech. 21(1): 1-10, 2011 (June)

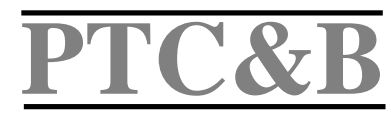

\title{
Callus Culture of Arceuthobium americanum Nutt. ex Englem. and Explant Response to Varying Auxin and Cytokinin Concentrations
}

\author{
Lyssa L. Martin, Cynthia Ross Friedman* and Ronald G. Smith \\ Department of Biological Sciences, Thompson Rivers University (TRU), 900 McGill \\ Road, Kamloops, BC, Canada V2C 0C8 \\ Key words: Callus culture, Arceuthobium americanum, Explant, Response, \\ Cytokinin, Insensitivity
}

\begin{abstract}
The lodgepole pine dwarf mistletoe Arceuthobium americanum is a severe pest in coniferous forests of western North America. To facilitate laboratory studies of this obligate parasite, a modified White's medium was used for in vitro culture; the concentrations of IAA and Kn were varied to determine optimal IAA/Kn ratios. It was found that explant health was related to the concentration of IAA $(p=0.008)$, but not $\mathrm{Kn}(\mathrm{p}=0.937)$, and that explants were healthiest at an IAA/Kn ratio of 0.1 . Radicular apices were generated at IAA/Kn ratios of 1.0 or greater, but no shoot organogenesis was observed. These data suggest that $A$. americanum is more sensitive to auxins than cytokinins. Parasites of plants are known to secrete high levels of cytokinins, which stimulate the host to shuttle nutrients to the infected area, and so we suspect that $A$. americanum has reduced cytokinin sensitivity.
\end{abstract}

\section{Introduction}

The genus Arceuthobium M. Bieb. (Viscaceae), also known as dwarf mistletoes, comprises a group of obligate aerial parasites on Pinaceae and Cupressaceae. Arceuthobium americanum Nutt. ex Englm. (lodgepole pine or American dwarf mistletoe), is a severe pest in coniferous forests of western North America, where it most commonly infects jack pine (Pinus banksiana Lamb.) and two variants of lodgepole pine: Pinus contorta Dougl. ex Loud. var. latifolia Engelm. and P. contorta Dougl. ex Loud. var. murrayana Grev. and Balf. Engelm. (Brandt 2006). It is a small, dioecious flowering plant with an exposed aerial portion, a system of root-like haustoria, and a remarkable habit of explosively discharging its seeds. The haustoria, collectively called the endophytic system, extensively penetrate the host's cortex, vascular cambium, phloem, and ultimately the xylem. As a result, the structural integrity of infected wood is compromised, making it

${ }^{*}$ Author for correspondence. 
largely useless. In North American forests, extensive A. americanum infections have a negative impact on the forestry economy.

Long term studies of living $A$. americanum are challenging. The parasite is dependent on its host for water, minerals and some photosynthate; as such, $A$. americanum specimens live only a short time without their host plant (Brandt et al. 2005). Cut pine branches infested with mistletoe are only viable for a few days at room temperature and a month at most at $4^{\circ} \mathrm{C}$. If $A$. americanum could be cultivated in the lab via cell culture, the ease of obtaining samples could allow for a better understanding of $A$. americanum physiology. The anatomy of the inaccessible haustoria and the mechanism for explosive discharge could be explored. Live tissue studies could also make the development of an elusive control mechanism a reality.

Several related dwarf mistletoe species have been cultured in vitro, although it is difficult to quantify the precise auxin to cytokinin ratios used in these mistletoe studies. It is well-known that relatively high ratios of auxin to cytokinin induce root organogenesis in explants, while low ratios induce shoot organogenesis (Fowler 2000). However, the exact ratios are different for every species. These hormones are also factors for plant cell survival, so their presence promotes explant health (Moubayidin et al. 2009). Using both seeds and adult tissue, Bonga and Chakraborty (1968) cultured Eastern dwarf mistletoe, A. pusillum Peck. However, cytokinin had not been identified at the time of this work, so neither the effect of cytokinin nor the optimal ratio of auxin to cytokinin was evaluated. In 2001, Deeks et al. successfully cultured the hemlock dwarf mistletoe, A. tsugense (Rosendahl) G. N. Jones, using germinating seeds rather than adult tissue to yield callus. These authors stated that the optimal ratio for generating callus was $0.52,4-\mathrm{D}$, an auxin, to BAP. For purposes of replication, this value is sensible. However, in their study, the culture medium was supplemented with coconut milk, which contains zeatin, making the total auxin to cytokinin ratio much smaller than 0.5 .

The purpose of this investigation was to determine if $A$. americanum could be grown in cell culture as callus from stem explants. Additionally, the optimal ratios of IAA to $\mathrm{Kn}$ were sought with respect to inducing callus formation, maintaining healthy explants, inducing root organogenesis, and inducing shoot organogenesis. If $A$. americanum could be cultivated in the laboratory a better understanding of $A$. americanum physiology, including haustorial anatomy and explosive discharge, could be realized.

\section{Materials and Methods}

Healthy, mature Arceuthobium americanum stem tissue samples were collected from an infected lodgepole pine stand at Stake Lake $(20 \mathrm{~km}$ southwest of 
Kamloops, British Columbia, Canada, 50 30'58.22"N, 120 28'49.99"W) in July and August of 2009. The mistletoe stems were vacuum sterilized in $70 \%(\mathrm{v} / \mathrm{v})$ ethanol for $10 \mathrm{~min}$ in a sealed vacuum flask evacuated with a vacuum pump. This was followed by surface sterilization in $6 \%$ sodium hypochlorite $(\mathrm{w} / \mathrm{v})$ for $5 \mathrm{~min}$, then a $5 \mathrm{~min}$ wash of sterile deionized water. Sterilized stems were cross-sectioned in to $1.5 \mathrm{~mm}$ long sections with a sterile scalpel. Modified White's medium (Deeks et al. 2001), $\mathrm{pH}$ 5.8, was prepared by adding the macronutrients (Table 1),

Table 1. The components of White's medium, without added hormones, categorized into macronutrients, mineral salts and carbon sources present in large quantities; micronutrients, mineral salts present in trace amounts; and vitamins, non-mineral essential cofactors of metabolism (Deeks et al. 2001).

\begin{tabular}{|c|c|c|}
\hline Component & Concentration $(\mathrm{mg} / \mathrm{l})$ & Concentration $(\mu \mathrm{M})$ \\
\hline \multicolumn{3}{|l|}{ Macronutrients } \\
\hline $\mathrm{MgSO}_{4} .7 \mathrm{H}_{2} \mathrm{O}$ & 360 & 1460 \\
\hline $\mathrm{Ca}\left(\mathrm{NO}_{3}\right)_{2} .4 \mathrm{H}_{2} \mathrm{O}$ & 260 & 1100 \\
\hline $\mathrm{Na}_{2} \mathrm{SO}_{4}$ & 200 & 1408 \\
\hline $\mathrm{NaH}_{2} \mathrm{PO}_{4}$ & 165 & 1375 \\
\hline $\mathrm{KNO}_{3}$ & 80 & 791.3 \\
\hline $\mathrm{KCl}$ & 65 & 871.9 \\
\hline Citric acid & 7 & 36.43 \\
\hline $\mathrm{Fe}\left(\mathrm{NO}_{3}\right)_{3}$ & 7 & 28.94 \\
\hline Sucrose & 20000 & 58430 \\
\hline Agar & 8000 & Not applicable* \\
\hline \multicolumn{3}{|l|}{ Micronutrients } \\
\hline $\mathrm{MnSO}_{4} \cdot \mathrm{H}_{2} \mathrm{O}$ & 2.3 & 13.61 \\
\hline $\mathrm{ZnSO}_{4} \cdot \mathrm{H}_{2} \mathrm{O}$ & 0.5 & 2.786 \\
\hline $\mathrm{H}_{3} \mathrm{BO}_{3}$ & 0.5 & 8.087 \\
\hline $\mathrm{CuSO}_{4} .5 \mathrm{H}_{2} \mathrm{O}$ & 0.025 & 0.1001 \\
\hline $\mathrm{Na}_{2} \mathrm{MoO}_{4} \cdot \mathrm{H}_{2} \mathrm{O}$ & 0.025 & 0.1033 \\
\hline $\mathrm{CoCl}_{2} .6 \mathrm{H}_{2} \mathrm{O}$ & 0.05 & 0.2101 \\
\hline \multicolumn{3}{|l|}{ Vitamins } \\
\hline Glycine & 7.5 & 99.91 \\
\hline Thiamine & 0.25 & 0.7412 \\
\hline Niacin & 1.25 & 10.15 \\
\hline Calcium pantothenate & 0.025 & 0.1140 \\
\hline Pyridoxine & 0.025 & 0.1478 \\
\hline
\end{tabular}

*The molecular structure of agar is variable.

agar last, to $400 \mathrm{ml}$ of deionized $\mathrm{H}_{2} \mathrm{O}$ ( $\mathrm{pH}$ adjusted to 5.8). The medium was then autoclaved at $120^{\circ} \mathrm{C}$ and 15 PSI for $30 \mathrm{~min}$. The heat-labile vitamins were added to the medium through a $0.22 \mu \mathrm{m}$ filter (i.e., filter-sterilized) when the medium 
was below $58^{\circ} \mathrm{C}$. Medium was dispensed in $5 \mathrm{ml}$ aliquots into warmed test tubes; the filter-sterilized IAA and $\mathrm{Kn}$ were added to the $5 \mathrm{ml}$ of medium in the tubes in accordance with Table 2 (from 0 to $5 \mu \mathrm{M}$ ), resulting in 16 different treatments. The contents of each tube were poured into $60 \mathrm{~mm}$ culture dishes (Corning). After the media set, six cross sections were positioned on each culture dish in a laminar flow hood so that each cross section had a cut side in contact with the medium. The plates were kept in a large airtight container alongside beakers of water to keep the air hydrated; the beakers were topped-up with water weekly. Cultures were grown at room temperature $\left(25^{\circ} \mathrm{C}\right)$ in darkness, for periods ranging from 20 to 31 days. Three replicates were conducted with initiations ranging over a month.

Table 2. The concentration of IAA and Kn was varied in the media, resulting in 16 different treatments (labelled 1 to 16 in the body of the table).

\begin{tabular}{|c|c|c|c|c|c|}
\hline & \multicolumn{5}{|c|}{$\begin{array}{c}\text { Concentration of IAA in } \mu \mathrm{M} \\
\left(\mathrm{IAA} / \mathrm{Kn} \text { ratio }^{*}\right)\end{array}$} \\
\hline & & 0 & 0.5 & 2.5 & 5 \\
\hline \multirow{4}{*}{$\begin{array}{l}\text { Concentration } \\
\text { of } \mathrm{Kn} \text { in } \mu \mathrm{M}\end{array}$} & 0 & $1(0.0)$ & $2(0.5 / 0.0)$ & $3(2.5 / 0)$ & $4(5.0 / 0.0)$ \\
\hline & 0.5 & $5(0 / 0.5)$ & $6(1.0)$ & $7(5.0)$ & $8(10.0)$ \\
\hline & 2.5 & $9(0.0 / 2.5)$ & $10(0.2)$ & $11(1.0)$ & $12(0.5)$ \\
\hline & 5 & $13(0.0 / 2.5)$ & $14(0.1)$ & $15(0.5)$ & $16(1.0)$ \\
\hline
\end{tabular}

*The term "ratio" is not technically correct with respect to those treatments lacking either or both hormones, but for simplicity and consistency, we used the term "IAA/kinetin ratio" when referring to any treatment.

The health of cultures was assessed visually based on colour and turgidity; sections that were green and turgid were considered "healthy," while brown, yellow, or limp sections were considered "unhealthy". The health of the sections was visually assessed four times weekly. After 21 days, the total number of healthy days was determined for each treatment. Chi squared tests of association (Minitab) were used to determine if hormone concentration affected the health of the cultures in each of the three trials and in the sum of the three trials. Chi squared tests of association (Minitab) were also used to determine if the non-zero hormone concentrations had different effects on the cultures. One and two way ANOVAs (Minitab) were used to determine how hormone concentration affected the health of the cultures for the sum of the three trials including and excluding treatments when one or both hormones had a concentration of $0 \mu \mathrm{M}$. A one way ANOVA (Minitab) was used to determine if IAA to $\mathrm{Kn}$ ratio was related to culture health. 


\section{Results and Discussion}

Small callus-like outgrowths were common on the explants in all treatments (Fig. 1A-E). In some explants, cells representing incipient callus were observed growing out from the base of the explant directly onto the medium (Fig. 1F). The small outgrowths were randomly distributed among treatments, but were not numerous enough to determine if a statistically significant relationship existed between hormone treatment and frequency of appearance. The same was true for the cells dividing and spreading onto the medium. Both of these phenomena indicated that cells were actively dividing and developing into callus.
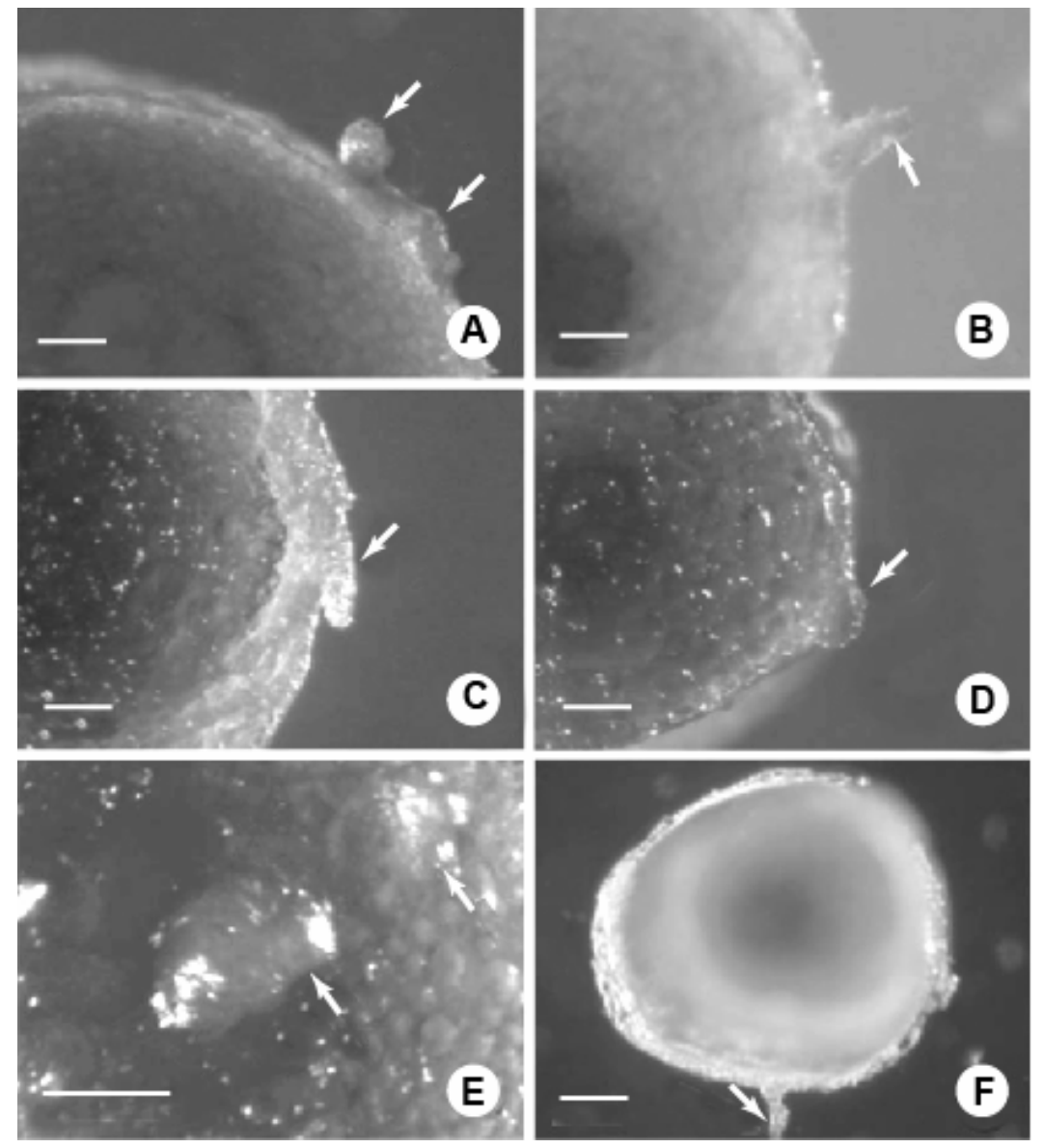

Fig. 1. Callus initiation from Arceuthobium americanum explants. Small outgrowths of cells (arrows) were common to all treatments (A-F). Some outgrowths bulged outward (A-D), while others grew upward from the explant (E). Other explants had cells spreading from the base out onto the medium (F). Hormone concentration in $\mathrm{A}$ and $\mathrm{F}=0.5 \mu \mathrm{M}$ IAA, $0.5 \mu \mathrm{M}$ Kn (treatment 6); in $\mathrm{B}=2.5$ $\mu \mathrm{M}$ IAA, $0.5 \mu \mathrm{M} \mathrm{Kn}$ (treatment 7); in $\mathrm{C}=0.5 \mu \mathrm{M}$ IAA, $2.5 \mu \mathrm{M}$ Kn (treatment 10); in $\mathrm{D}=2.5 \mu \mathrm{M}$ IAA, $2.5 \mu \mathrm{M}$ Kn (treatment 11); and in $\mathrm{E}=5.0 \mu \mathrm{M}$ IAA, $2.5 \mu \mathrm{M}$ Kn (treatment 12). Bar in A-D = 100 $\mu \mathrm{m}$; bar in $\mathrm{E}=50 \mu \mathrm{m}$; bar in $\mathrm{F}=200 \mu \mathrm{m}$. 
Solid conical projections grew from the base of the explants in treatments 4 , 7, 8 and 16, corresponding to $5.0 \mu \mathrm{M}$ IAA and $0 \mu \mathrm{M} \mathrm{Kn}$ (5.0/0 IAA/Kn ratio); 2.5 $\mu \mathrm{M}$ IAA and $0.5 \mu \mathrm{M} \mathrm{Kn}(5.0 \mathrm{IAA} / \mathrm{Kn}$ ratio); $5.0 \mu \mathrm{M}$ IAA and $0.5 \mu \mathrm{M} \mathrm{Kn}(10$ IAA/Kn ratio); and $5.0 \mu \mathrm{M}$ IAA and $5.0 \mu \mathrm{M} \mathrm{Kn}(1.0 \mathrm{IAA} / \mathrm{Kn}$ ratio), respectively (Fig. 2A-C). Their emergence was apparently triggered by auxin, as they appeared only in treatments with an IAA/Kn ratio of 1 or more, with at least 2.5 $\mu \mathrm{M}$ IAA. Each projection strongly resembled a penetration wedge or "radicular apex" that germinating dwarf mistletoe seeds use to enter their host (Hawksworth and Wiens 1996). Therefore, it is likely that these projections are manifestations of haustoria, the dwarf mistletoe's modified root system.

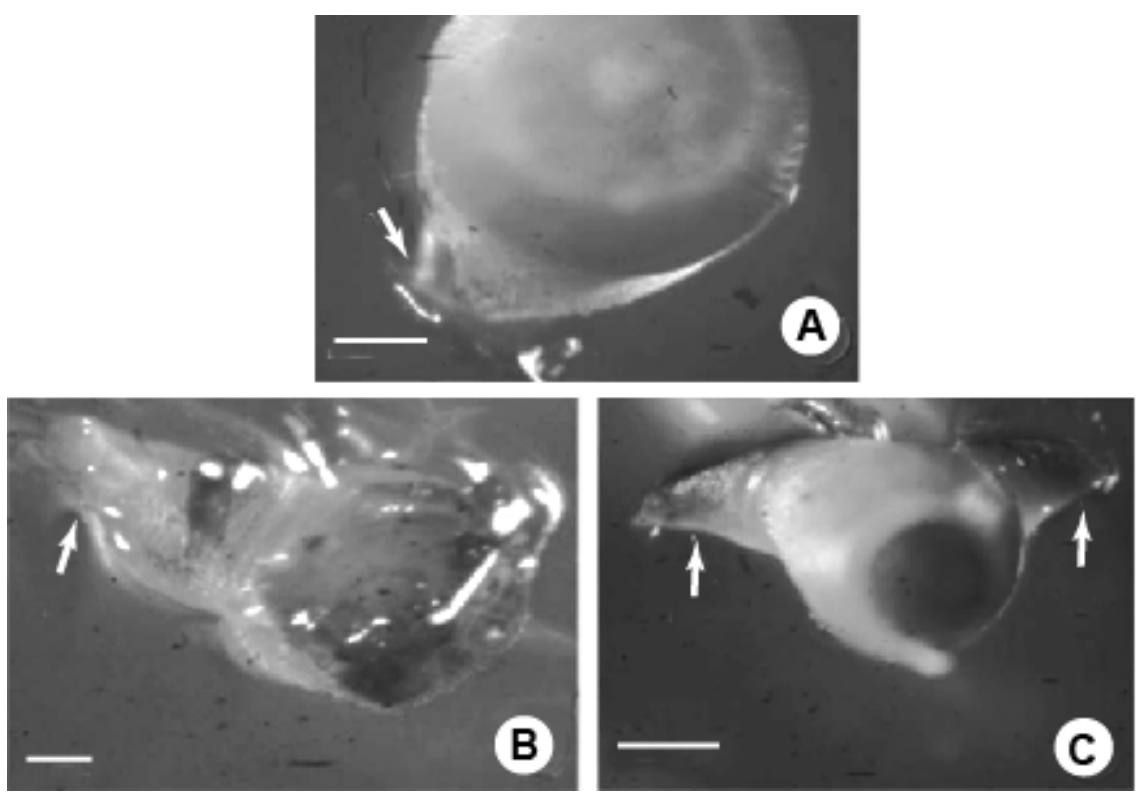

Fig. 2 Arceuthobium americanum explants from treatments 4, 7, 8 and 16 produced conical projections (arrows) that grew from their bases into the medium. Growth of a single projection was most common (A and $B)$, although some grew two or more (C). Hormone concentration in $A=5.0 \mu \mathrm{M}$ IAA, $0 \mu \mathrm{M} \mathrm{Kn}$ (treatment 4); in $\mathrm{B}=2.5 \mu \mathrm{M}$ IAA, $0.5 \mu \mathrm{M}$ Kn (treatment 7); and in $\mathrm{C}=5.0 \mu \mathrm{M}$ IAA, $0.5 \mu \mathrm{M} \mathrm{Kn}$ (treatment 8). Results from treatment 16 are not shown. Bars in $\mathrm{A}$ and $\mathrm{B}=200 \mu \mathrm{m}$; bar in $\mathrm{C}=500 \mu \mathrm{m}$.

Having a minimum IAA/Kn ratio of 1 for the induction of root organogenesis in dwarf mistletoe culture is somewhat low relative to classically-studied plants like tobacco (Nicotiana tabacum L.), for example, in which an auxin to cytokinin ratio of $10: 1$ is the lowest at which roots will develop in culture (Skoog and Miller 1956). However, the dwarf mistletoe radicular apex, for as much as it shares some function with true plant roots, also shares anatomy with shoots, as it possesses chlorophyll and stomata, and lacks a root cap (Hawksworth and Wiens 1996). Thus, the fact that IAA drove development of root-like organs in dwarf 
mistletoe culture, but with a ratio of auxin to cytokinin somewhat lower than typical plants, is logical considering the dual nature of the dwarf mistletoe radicular apex. No true shoots, though, were obtained in culture, even at the highest concentrations of $\mathrm{Kn}$ or the lowest IAA to Kn ratios.

Hormone concentration had an effect on the number of days a culture was healthy in all three replicates ( $\mathrm{p}<0.001, \mathrm{p}<0.001$, and $\mathrm{p}=0.038$, respectively) and in the sum of the replicates $(\mathrm{p}<0.001)$. Explants exposed to both IAA and $\mathrm{Kn}$ remained healthier for more days than explants lacking one or both hormones, suggesting that both auxin and cytokinin are required for survival of the explant (Moubayidin et al. 2009). Treatment 14 , with $0.5 \mu \mathrm{M}$ IAA and $5.0 \mu \mathrm{M} \mathrm{Kn}(0.1$ IAA/Kn ratio) was healthy for the longest period of time in all three replicates (Fig. 3).

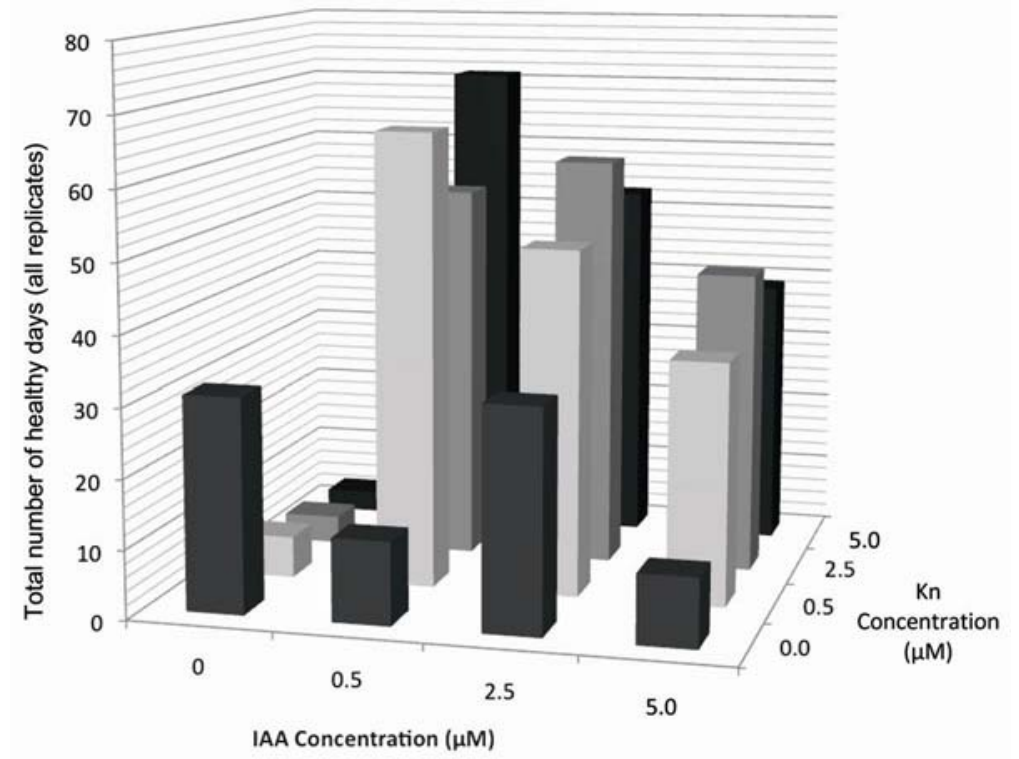

Fig. 3. Explant health in Arceuthobium americanum as governed by hormone concentration. The total number of healthy days for all three replicates shown as a function of both IAA and Kn concentration demonstrates that treatment $14(0.5 \mu \mathrm{M}$ IAA and $5.0 \mu \mathrm{M} \mathrm{Kn})$ was healthiest for the longest period of time, and also indicates that both hormones are required for explant health. Dark grey shading $=0.0 \mu \mathrm{M} \mathrm{Kn}$; light grey shading $=0.5 \mu \mathrm{M} \mathrm{Kn}$; medium grey shading $=2.5 \mu \mathrm{M}$ Kn; black shading $=5.0 \mu \mathrm{M} \mathrm{Kn}$.

A two way ANOVA revealed that the number of days a culture is healthy varies with IAA concentration $(p=0.033)$, but not with Kn concentration $(p=$ 0.348). A one way ANOVA examining the number of healthy days for IAA treatments, including treatments with zero hormones, confirmed that treatments containing IAA at any concentration are healthy for longer than those treatments with no IAA $(p=0.028)$. A one way ANOVA examining the number of days an 
explant was healthy with respect to varying IAA concentrations (with zero IAA and $\mathrm{Kn}$ treatments excluded) indicated that treatments with $0.5 \mu \mathrm{M}$ IAA were healthy for longer periods than treatments with $1.0 \mu \mathrm{M}$ IAA, which in turn were healthy for longer than treatments with $5 \mu$ M IAA $(p=0.008)$. Similarly, a one way ANOVA examining the number of healthy days for $\mathrm{Kn}$ treatments, including treatments with zero hormones, confirmed that treatments with no Kn were not as healthy as those with $\mathrm{Kn}(\mathrm{p}=0.028)$. However, a one way ANOVA examining the number of healthy days for $\mathrm{Kn}$ treatments excluding treatments with no $\mathrm{Kn}$ revealed that there was no significant difference among them $(\mathrm{p}=$ 0.937).

When the IAA to Kn ratio for each treatment was compared to the total number of healthy days across all replicates, a trend emerges in which explants remain healthy for longer periods at lower IAA/Kn ratios. While a one way ANOVA indicated that this relationship was not significant $(p=0.117)$, the trend is certainly noteworthy, as it appears that an excess of cytokinin relative to auxin is required for explant health. Recall that treatment 14 had the lowest IAA/Kn ratio (0.1) and was the healthiest treatment in all three replicates (Fig. 3).

In this study, explants did not respond to "normal" Kn concentrations; instead, the highest levels of Kn promoted explant health without triggering true shoot production, even at the lowest IAA to Kn ratios. These results imply that Arceuthobium americanum has a reduced sensitivity to Kn, which makes sense in the context of its parasitic lifestyle. Cytokinins are often secreted by parasites of plants to stimulate growth in the infected area; this way, a parasite can stimulate its host plant to donate nutrients (Greene 1980). In addition, increasing cytokinin levels in a tissue creates a nutrient sink. The bacterium Corynebacterium fascians (Tilford) Dowson is a surface pathogen of the garden ornamental Lathyrus odoratus L. (the sweat pea). In culture, it secretes high levels of the cytokinins zeatin and 2iP. The secretion of cytokinins in affected areas induces the formation of a witch's broom, where several lateral shoots develop at once. Normally, the auxin to cytokinin ratio in a plant is such that the lateral buds remain dormant, but the addition of cytokinin to the system releases them from inhibition and allows them to develop, shuttling nutrients from other areas of the host plant.

When Arceuthobium americanum infects lodgepole pine, it induces the formation of witches' brooms (Tinnin et al. 1982, Brandt et al. 2005). Additionally, Schaffer et al. (1983) have shown that witch's broom formation in ponderosa pine (Pinus ponderosa Dougl.), induced by the pineland dwarf mistletoe (Arceuthobium vaginatum (Willd.) J. Presl.), is related to cytokinin activity. These workers found that the cytokinin levels of healthy tissue in the infected pine were the same as that of uninfected pine, while the cytokinin levels 
of infected branches were elevated. Furthermore, the highest level of cytokinin was detected in the xylem of the shoots of Arceuthobium vaginatum itself. Witch's broom formation in pine is a direct result of exposure to elevated level of cytokinins secreted directly by the dwarf mistletoe parasite as well as released by the pine as part of its response to infection. Either way, a dwarf mistletoe plant's exposure to cytokinin is abnormally high relative to typical plants, especially since the cytokinin is most concentrated in the shoots of the mistletoe. The cytokinin-dependent gene regulation of the mistletoe would be undermined if the mistletoe's cytokinin sensitivity was comparable to that of free living plants. If the mistletoe has adjusted its optimal auxin to cytokinin ratio to one much lower, than it would be able to reap the benefits of high cytokinin concentration, like acquiring more nutrients from its host, while retaining control of its own gene regulation. Since the mistletoe retains its apical dominance under high cytokinin conditions even when the pine fails to, it must have reduced its sensitivity to cytokinin.

Deeks et al. (2001) germinated $A$. tsugense seeds in vitro to generate callus, citing an optimal ratio of 0.5 2,4-D to BAP. However, in the Deeks et al. study, the culture medium was supplemented with zeatin-containing coconut milk, making the total auxin to cytokinin ratio smaller than their suggested value of 0.5. Thus, this callus-generating study by Deeks et al. (2001) supports the conclusion presented here, namely, dwarf mistletoe callus cultures require elevated Kn because these plant parasities have reduced sensitivity to cytokinins.

In conclusion, this study lays the foundation to continue culturing Arceuthobium americanum. If $A$. americanum could be cultivated in the lab, both tissue and DNA/RNA samples would be easier to obtain, and direct experimental manipulation could be more readily performed. Live tissue studies carried out in culture could one day enable the development of a control mechanism for dwarf mistletoes.

\section{Acknowledgement}

The authors gratefully acknowledge Simon Shamoun for his White's medium recipe as well as for encouragement and support. Thanks to Christine Peterson and Lyn Baldwin for instruction in plant sectioning; to Carolynne Fardy for technical assistance; to Louis Gosselin for use of his dissecting microscope; to Nancy Flood for her help with statistics. Special thanks to Arvin Dwarka and Andrew Owusu for help with specimen collection. Funding for this project was supplied by a Natural Sciences and Engineering Research Council (NSERC) of Canada Discover Grant awarded to CRF. 


\section{References}

Bonga JM and Chakraborty C (1968) In vitro culture of a dwarf mistletoe, Arceuthobium pusillum. Can. J. Bot. 46: 161-164.

Brandt J (2006) Life cycle of Arceuthobium americanum on Pinus banksiana based on inoculations in Edmonton, Alberta. Can. J. For. Res. 36: 1006-1016.

Brandt JP, Hiratsuka Y and Pluth DJ (2005) Germination, penetration, and infection by Arceuthobium americanum on Pinus banksiana. Can. J. For. Res. 35: 1914-1930.

Deeks SJ, Shamoun SF and Punja ZK (2001) In vitro germination and development of western hemlock dwarf mistletoe. Plant Cell Tiss. Org. 66: 97-105.

Fowler MR (2000) Plant Cell Culture, Laboratory Techniques. I: The Encyclopedia of Cell Technology, New York, Wiley, pp. 994-1004.

Greene EM (1980) Cytokinin production by microorganisms. Bot. Rev. 46: 25-74.

Hawksworth FG and Wiens D (1996) Dwarf mistletoes: biology, pathology, and systematics. USDA For. Serv. Handb. No. 709.

Moubayidin L, Di Mambro R and Sabatini S (2009) Cytokinin-auxin crosstalk. Trends Plant Sci. 14: 557-562.

Schaffer B, Hawksworth FG, Wullschleger SD and Reid P (1983) Cytokinin-like activity related to host reactions to dwarf mistletoes (Arceuthobium spp.). For. Sci. 29: 66-70.

Skoog F and Miller CO (1956) Chemical regulation of growth and organ formation in plant tissue cultures in vitro. Symp. Soc. Exp. Biol. 11: 118-31.

Tinnin RO, Hawksworth FG and Knutson DM (1982) Witches' broom formation in conifers infected by Arceuthobium spp.: an example of parasitic impact upon community dynamics. Am. Midl. Nat. 107: 351-359. 